\title{
Response Inhibition and Impulsiveness in Smoking and Non-Smoking Young Tattooed Women
} \author{
Weizman $^{2,8}$ \\ ${ }^{1}$ Beer-Ya'akov-Ness Ziona Mental Health Center, Forensic Psychiatry Division, Israel \\ ${ }^{2}$ Sackler Faculty of Medicine, Tel Aviv University, Israel \\ ${ }^{3}$ Hermeneutics and Culture Department, Bar-Ilan University, Israel \\ ${ }^{4}$ Department of Neuro-Pathopsychology, L.S. Vygotsky Institute of Psychology, Russia \\ ${ }^{5}$ Environics Analytics, Toronto, Canada \\ ${ }^{6}$ Psychological Department, University of Haifa, Israel \\ ${ }^{7}$ Comparative Literature Department, Bar-Ilan University, Israel \\ ${ }^{8}$ Research Unit, Geha Mental Health Center and Felsenstein Medical Research Center, Israel \\ ${ }^{\#}$ Equal contribution
}

Semion Kertzman ${ }^{1,2 *}$, Alex Kagan ${ }^{3,4} \#$, Michael Vainder ${ }^{5}$, Omer Hegedish ${ }^{1,6}$, Rina Lapidus ${ }^{3,7}$ and Abraham

Submission: January 19, 2021; Published: February 23, 2021

*Corresponding author: Semion Kertzman, Beer-Ya'akov-Ness Ziona Mental Health Center, Forensic Psychiatry Division, Sackler Faculty of Medicine, Tel Aviv University, Israel

\begin{abstract}
According to previous studies, tattooing may express addiction-like behavior. A common problem of tattooed individuals is impulsive behavior. This study investigated the interaction between response inhibition, impulsiveness and smoking in young, tattooed women. Women aged 18-35 years with $(\mathrm{N}=60)$ and without $(\mathrm{N}=60)$ tattoos completed a Go/NoGo task to assess response inhibition and the Barratt Impulsivity Scale (BIS-11). Significantly higher rates of smoking, higher BIS-11 scores and larger impairment in response inhibition on the Go/NoGo task were observed in the tattooed women. The tattoo effect in the Go/NoGo task and the BIS-11 measures remained significant after adjustment for smoking status. Significant correlation was found between slowness of response-time in the Go/NoGo task and the total and non-planning impulsivity scores of the BIS-11. No significant associations were found between the BIS-11 and number of commission/omission errors and variability of response time in the Go/NoGo task. This study is the first to demonstrate that tattooed women exhibit lower response inhibition capacity and higher impulsiveness than non-tattooed controls. Smoking does not explain the psychometric/neurocognitive differences between tattooed women and controls.
\end{abstract}

Keywords: Tattoo; The Go/NoGo task; The Barratt Impulsivity Scale; Tobacco smoking.

\section{Introduction}

Most studies published in the last 10 years suggested that in Western societies, especially among youth, tattooing is becoming more popular [1]. A predisposing factor that may lead to a tattooing behavior is impulsivity, as a variant of risk-taking actions [2-5]. Getting a tattoo was associated with impulsivity-related constructs such as illegal activities, gambling, dropping out of school, greater numbers of lifetime sexual partners, unprotected sex, suicidal attempts, violence and death by homicide [6-14]. In addition, getting a tattoo is associated with alcohol and illicit drug use disorders [15-19]. Tattoos may express addictive-like behavior, that may be associated with release of endorphins due to the painful penetration of the body, anesthetizing and entailing a positive feeling (see for review: Wohlrab, Stahl, \& Kappeler (2007) [20]). Following this line of evidence, high numbers of tattoos are associated with addiction to body modification [21]. 
Impulsivity is conceptualized as acting without taking into consideration the negative consequences of the actions, namely, 'act before you think' [22]. Impulsivity is the inability to suppress responses that are inappropriate in a given context [23]. The ability to control an action is a facet of impulse control that may prevent further tattooing by allowing one to stop the tattoo getting behavior. Failure of such control may promote heavy tattooing due to inability to stop this risk-taking behavior. The Go/NoGo task was developed to assess response dimension of inhibitory control by examining the ability to both execute responses to Go and suppress/inhibit responses to NoGo signals (for further details see Bari \& Robbins (2013) [24]). It was proposed that behavioral phenomena such as impulsiveness and substance use disorders should be regarded as a part of the disinhibitory disorder spectrum [25]. Smoking is prevalent among individuals with tattoos $[26,27]$. The association between having tattoos and smoking seems to be related to addictive behavior [20]. Previous studies clearly implicate impulsivity as a precursor for smoking [28-30]. Smoking was also reported to be associated with impairment of response inhibition [31]. Thus, both impulsiveness and inhibition may be potential contributors to the relationship between smoking and tattooing. In addition, smoking behavior may be a significant confounder of both impulsiveness and inhibition measures in tattooed populations.

The major questions of the current study were: (1) Do tattooed women demonstrate worse response inhibition, as measured by a Go/NoGo task, than women without tattoos? (2) In tattooed women, is there a significant correlation between impulsiveness as measured by the Barratt Impulsivity Scale (BIS-11) [32] and the response inhibition capacity as measured by the Go/NoGo task performance? (3) Are motor, non-planning and attentional impulsiveness subscales of the BIS- 11 associated with impaired response inhibition measures in tattooed women? (4) Is smoking status associated with inhibition impairments in tattooed women? (5) Which of the response inhibition parameters is a predictor for tattooing?

Within the Go/NoGo performance test we assessed three parameters of the response inhibition domain. As tattooing behavior is associated with impulsiveness it was expected that, similar to findings of previous studies in participants with impulsive behavior, the following response characteristics would be detected in the tattooed women: (i) excessive slowness in response [33-36], (ii) high rate of commission errors [37] and, (iii) low omission rate $[38,39]$ and (iv) large variability of response time $[40,41]$. Despite accumulating evidence that a range of impulsive behaviors may be the precursors of tattooing, the inhibition deficits in these individuals have not been studied. Moreover, in individuals with tattoos, the association between response inhibition and self-reported impulsiveness has not been investigated so far. Although tattooing behavior is often suggested to be a masculine trait [42] it has been reported that women comprise about $45-65 \%$ of the tattooed population
[43]. Though the prevalence of body modification increases, data regarding impulsiveness in non-psychiatric and non-prison populations are few and controversial, especially in female populations $[44,45]$. This investigation of non-psychiatric, nonprison female populations is important because elevated levels of impulsivity and disinhibition may indicate that tattooing behavior is associated addictive characteristics.

\section{Material and methods}

\section{Sample}

As described previously [46] all participants (tattooed and non-tattooed women) were recruited by means of advertisements posted at universities, through personal contacts and social networks (Facebook). They were asked to take part in a research project investigating decision making styles in both, tattooed women and those without tattoos. All participants were recruited throughout the Tel Aviv area between March 2012 and July 2012. The participants in the two groups (research and control) were either holding a job, or students or graduates and came from a similar socioeconomic background. Participation in the study was voluntary. Compensation for participating in the study consisted of a free-of-charge consultation regarding their inhibition capacity and of professional advice regarding their neurocognitive and personality assessments. The study was approved by the Bar-Ilan University Review Board (Ramat Gan, Israel) and was conducted in individual sessions that included an explanation of the study purpose and aims. Participants then signed consent forms. The duration of the individual sessions was up to an hour and half. and the entire lasted for a period of five months.

The study included 60 women with current tattoos (women who had tattoos that were removed were not included in the study), aged 18 to 35 years ( $M=28.4, S D=5.95)$. Fifty eight percent of the tattooed women had more than one tattoo. The participants in the study were either employed or students and graduates with the following distribution in level of education: high school diploma or lower $-46.7 \%$, first university degree $-25 \%$, second university degree- $23.3 \%$, and philosophy degree $-5 \%$.

We analyzed only tattooed women in order to avoid gender differences on the impulsive measures $[47,48]$. The exclusion criteria were neurological disorders, mental retardation, alcohol and substance abuse or dependence (other than tobacco smoking), major psychiatric disorders and treatment with any psychiatric medication. Fifty five percent of the tattooed group were smokers. A semi-structured interview that included a 20-item measure of tattooing characteristics was conducted by a researcher (AK). The control group included 60 non-tattooed women of similar age range: $18-35$ years old $(M=28.5, S D=5.43)$. Education level in the control group was distributed as follows: high school diploma or lower - $25 \%$, undergraduate university degree $-28.3 \%$, Master's degree $-41.7 \%$ and Doctoral degree - 5\%. All participants completed an interview, regarding the following areas: medical 
history, illicit drug use, family and personal psychiatric history. None of the participants in the control group were maintained on a psychopharmacologic treatment. Exclusion criteria for the nontattooed control women (C) included any current or past DSM-IVTR axis I psychiatric disorder. Only $10 \%$ of participants from this group smoked regularly.

\section{Instruments}

\section{Response inhibition measure: The complex Go/NoGo task}

We applied a computerized variant of the Go/NoGo task (AnimaScan Ltd, Ashdod, Israel, 2000), as described previously [49]. The Go/NoGo task primarily reflects the ability to suppress a very potent (but not yet initiated) response. In order to investigate pure response-inhibition deficits, we used a simple situation and controlled for confounding factors. To this end, a computerized version of the tasks was designed so that it involved a minimal amount of working memory and neutralized stimuli in order to avoid the possibility of emotional bias on the performance. Participants were shown a series of stimuli consisting of a red or a black square, requested to press a button immediately on seeing a red square (Go signal), and not press it on seeing a black square (NoGo signal). Since previous studies suggested that the speed at which stimuli are presented is critical for establishing inhibitory control on the Go/NoGo task, the squares were displayed on the screen for a period of $100 \mathrm{~ms}$ each. The stimuli were presented in random order on a computer screen, at a rate of one stimulus every 2000 ms, against a white background. A constant interstimulus interval was chosen in order to minimize any orienting response due to unpredictability of stimulus occurrence. The whole experiment task lasts for $10 \mathrm{~min}$, and each condition (either CPT or Go/NoGo task) continues for $5 \mathrm{~min}$, without a pause between them. A total of 300 stimuli were divided into two successive conditions, each of which contained 150 stimuli. The CPT is a condition with frequent (80\%) NoGo events and the instructions to participants were to detect the rare Go stimuli (20\% frequency) and respond to them. The Go/NoGo is a condition with frequent Go $(80 \%)$ events, and the participants were instructed to avoid responding to the rare NoGo stimuli (20\%). Each participant performed two blocks in each condition [the CPT condition included block 1 (75 stimuli) and block 2 (76-150 stimuli); the Go/NoGo condition included block 3 (151-225 stimuli) and block 4 (226-300 stimuli)]. The order of task conditions was identical for all participants. It was found that this specific structure of the task may help to investigate the inhibition ability in situations involving a shift from rare Go stimuli (as in the CPT) to frequent Go stimuli (in the Go/NoGo condition).

On the Go trials the participants were instructed to press a response button "as quickly as possible" every time a red square was displayed. They responded by pressing a key on a computer keyboard with a dominant index-finger. They were instructed to keep their fingers over the key board and be ready to respond immediately.
There are two types of errors in this test. Errors of commission, which occur when the participant responds incorrectly to a black square; such a response is considered to be a measure of impulsivity. Errors of omission which occur when the participant omits pressing the button when a red square appears; such a response is considered to be a measure of inattention. In our case, reaction times to Go events were computed for trials in which the participants responded within $2100 \mathrm{~ms}$ of stimulus onset. Failure to respond to a Go event within a period of more than $2100 \mathrm{~ms}$ of stimulus onset or too quickly to have given consideration to the stimulus, i.e. less than $250 \mathrm{~ms}$ after red stimuli onset, were considered errors of omission. Errors of commission were defined as responses that occurred within $2100 \mathrm{~ms}$ of a NoGo stimulus onset. To ensure comprehension of the task instructions, participants were allowed a practice with 30 stimuli that familiarized them with the task. At the end of the practice session they were given feedback on the accuracy of their performance. Thus, in the practice sessions, accuracy was stressed, and participants were kept in training until they achieved a perfect score of $100 \%$ correct responses. Only afterwards did they start the actual test.

\section{Barratt impulsiveness scale (BIS-11)}

Trait impulsiveness was measured by the Barratt Impulsiveness Scale-11th Edition (BIS-11) [50]. The BIS is the most commonly administered self-assessment scale for impulsiveness, in both research and clinical settings [32]. The BIS-11 includes 30 statements on a 4-point Likert scale ranging from 1-4: 1= never/rarely, 2=sometimes, $3=$ frequently and $4=$ almost always/ always. The higher the total score, the higher the self-reported level of impulsivity (total scores range from 30 to 120). The BIS11 reveals three subscales: motor impulsiveness, which reflects acting without forethought (e.g., I do things without thinking); non-planning impulsiveness, which reflects emphasis on the present (e.g., I am more interested in the present than the future); and attentional impulsiveness, which reflects a reduced ability to maintain attention on a stimulus (e.g., I do not 'pay attention'; See Patton, Stanford, \& Barratt. 1995; for a list of items comprising BIS-11 subscales).

\section{Statistical analysis}

The data was analyzed using the SAS v9.4 statistical software package for Windows (SAS Institute Inc., Cary, NC, USA). In the first step, the differences in age, education and smoking habit between groups were examined. Student's t-test was used to analyze numerical variables (age and education) and a chi-square $(\chi 2)$ test for analyzing the categorical variable (smoking habit). Since preliminary analysis revealed that the groups differ in education and smoking habits, a series of repeated measure analyses of covariance (ANCOVAs) were conducted in the second step, in order to evaluate differences between groups in trial-to-trial performance. Those analyses used performance characteristics (response time, variability of response time, numbers of 
commission and omission errors) as dependent measures, group (Tattooed and Non-Tattooed) and smoking habit as betweenparticipant factors, condition ("CPT" and "Go/NoGo") and blocks $(1,2,3$ and 4$)$ as within-participant factors and education as covariate. Two conditions of the performance were examined: (i) CPT as the "target detection" condition, (ii) 'Go/NoGo' as the "inhibition ability" condition. A separate analysis was performed for the switching from block 2 to block 3 as a measure of remapping the strategy of responses (from ability to detect and react to, the Go stimulus to ability to withhold response to the NoGo stimulus). The third step of the analysis involved correlation analysis that evaluated the relationship between performance characteristics of the Go/NoGo task and the behavioral measurements.

\section{Results}

\section{Between-group comparison of the socio-demographic and BIS -11 characteristics}

As described previously [46] women with tattoos had significantly lower level of education than those without tattoos $14.53 \pm 2.77$ vs. $15.82 \pm 2.63$ correspondingly $(t=2.60, d f=118$, $\mathrm{p}=0.01$ ). They also had a higher rate of smoking than nontattooed women: $55 \%$ vs. $10 \%(\chi 2=27.69, \mathrm{df}=1, \mathrm{p}<0.0001)$. No differences in age were found between the two groups: $28.47 \pm$ 5.42 (tattooed) vs. $28.35 \pm 5.95$ (non-tattooed) $(\mathrm{t}=0.11, \mathrm{df}=118$, $\mathrm{p}=0.91$ ). Thus, only education and smoking were considered as covariates. In addition, the tattooed women exhibited significantly higher scores in all BIS-11 subscales: motor impulsiveness 20.83 \pm 4.02 (tattooed) vs. $17.57 \pm 2.98$ (non-tattooed) ( $\mathrm{F}=13.09, \mathrm{p}$ $=0.0004)$, nonblack-of-planning impulsiveness $24.88 \pm 3.82$ (tattooed) vs. $22.03 \pm 3.84$ (non-tattooed) ( $\mathrm{F}=16.01, \mathrm{p}=0.0001$ ), and attentional impulsiveness BIS-11 subscales $16.91 \pm 3.66$ (tattooed) vs. $14.42 \pm 2.98$ (non-tattooed) ( $\mathrm{F}=13.27, \mathrm{p}=0.0003$ ) [46]. Smoking correlated significantly only with motor impulsivity score $(F=7.90, p=0.006)$.

\section{Between-group comparison of the Go/NoGo performance}

Response time: A repeated measure ANCOVA was conducted using the groups (tattooed vs. non-tattooed) and smoking status as between-participants factor, conditions and block as repeat factors; and education as a covariate and the response time as the dependent variable. ANCOVA revealed a significant group effect $[F(1,116)=11.13, P=0.001]$ with effect size $\eta 2=0.09$. Tattooed women exhibited significantly larger response time than nontattooed women (Table 1 and Figure 1). There was a significant effect of conditions $[F(1,116)=11.33, P=0.001]$ with effect size $\eta 2=$ 0.09 , showing significant decrease in response time in both groups when the condition was changed from the CPT to the Go/NoGo task. No effect of block was present but a significant interaction of block with group $[F(1,116)=4.2, P=0.045]$ was found with effect size $\eta 2=0.03$, showing that the response time by block between the tattooed and non-tattooed group is significantly different. The decrease in response time from block to block in the tattooed group was faster than in the non-tattooed group. ANCOVA also revealed a significant smoking effect $[F(1,116)=3.98, P=0.048]$. Significant interaction was also found between block and smoking $[F(1,115)=9.47, P=0.003]$ with effect size $\eta 2=0.07$ indicating that the response time of smoking participants is different from that of non-smoking participants. Participants who smoke demonstrated faster decrease in response time than non-smokers (Figure 2). A three-way repeated measure ANCOVA was used with the group variable (tattooed or non-tattooed) and smoking status as between-participants factors and with blocks (block 2 and block 3 ) as repeated factors as well as with education as a covariate to assess the effect of switch from CPT to Go/NoGo conditions. There was a significant effect of switch $[\mathrm{F}(1,115)=12.08, \mathrm{P}=0.001]$ with effect size $\eta 2=0.08$, showing that mean response time in block 2 was higher than in block 3 but there was no significant interaction effect between group and switch.

Table 1: Adjusted means (and standard errors) of performance on the CPT and the Go/NoGo in tattooed and non-tattooed women.

\begin{tabular}{|c|c|c|c|c|}
\hline \multirow[t]{2}{*}{ Variable } & \multicolumn{2}{|c|}{ CPT } & \multicolumn{2}{|c|}{ Go/NoGo } \\
\hline & Block 1 & Block 2 & Block 3 & Block 4 \\
\hline \multicolumn{5}{|c|}{ Reaction Time } \\
\hline Tattoo & $416.55(11.61)$ & $419.44(12.09)$ & $389.43(12.72)$ & $386.51(13.14)$ \\
\hline Control & 391.19 (7.07) & $383.13(7.36)$ & $356.43(7.75)$ & $336.41(8.01)$ \\
\hline \multicolumn{5}{|c|}{ Reaction Time Variability } \\
\hline Tattoo & $68.44(4.96)$ & $64.47(4.39)$ & $75.99(4.42)$ & $80.30(4.78)$ \\
\hline Control & $68.26(8.14)$ & $56.10(7.21)$ & $74.87(7.26)$ & $63.17(7.86)$ \\
\hline \multicolumn{5}{|c|}{ Commission } \\
\hline Tattoo & $0.29(0.07)$ & $0.19(0.05)$ & $1.23(0.19)$ & $1.11(0.19)$ \\
\hline Control & $0.26(0.08)$ & $0.23(0.06)$ & $0.84(0.16)$ & $1.62(0.22)$ \\
\hline \multicolumn{5}{|l|}{ Omission } \\
\hline Tattoo & $0.12(0.04)$ & $0.24(0.06)$ & $0.56(0.21)$ & $0.47(0.16)$ \\
\hline Control & $0.01(0.05)$ & $0.05(0.08)$ & $0.54(0.18)$ & $0.42(0.19)$ \\
\hline
\end{tabular}




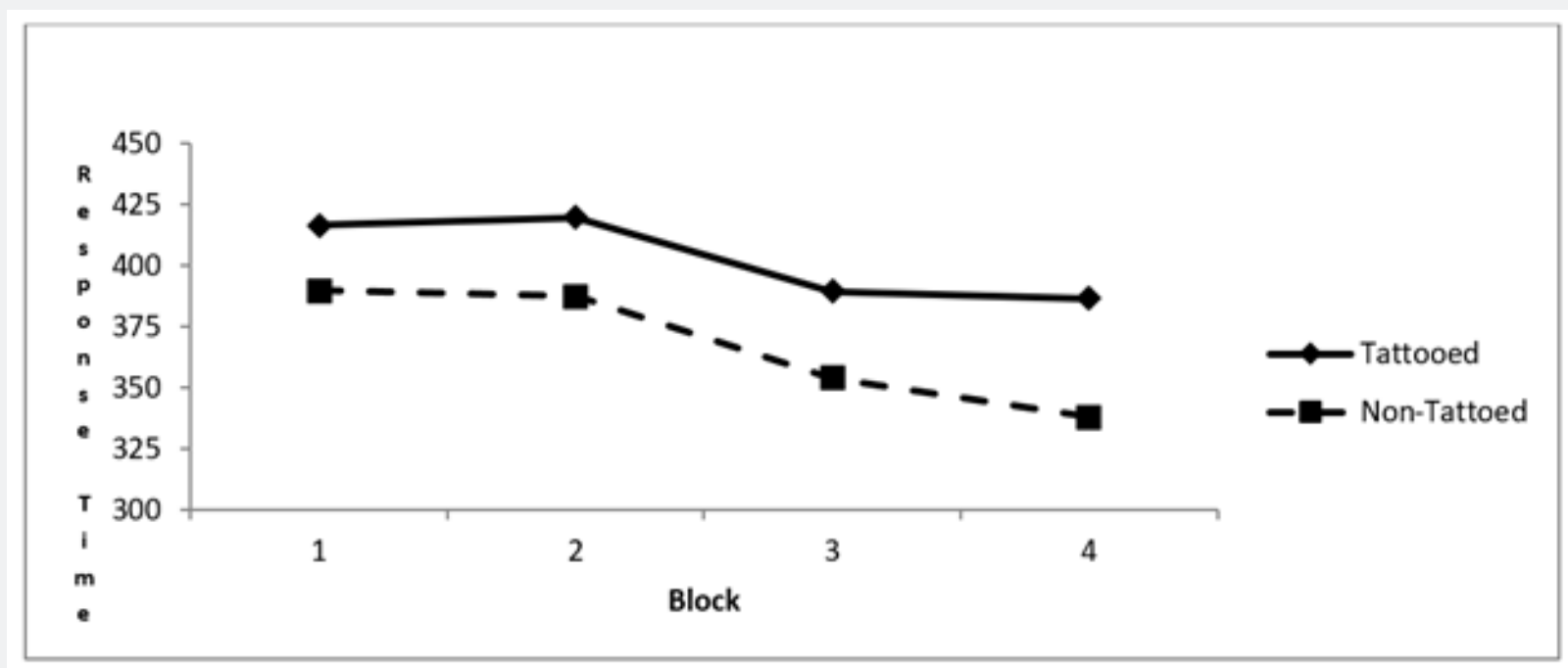

Figure 1: Mean of response time in tattooed and non-tattooed women.

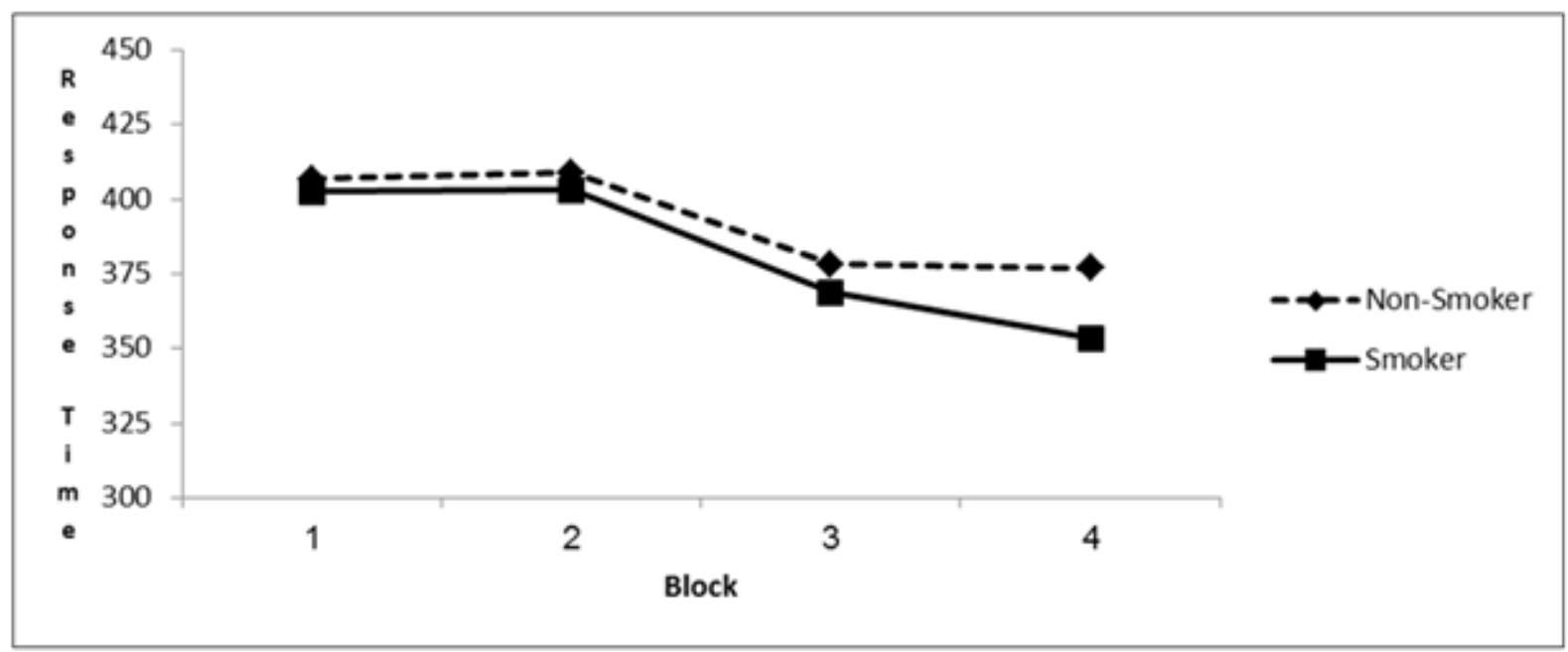

Figure 2: Mean of response time in smokers and non-smokers.

Variability in response time: A Four - way ANCOVA with group (tattooed vs. non-tattooed) and smoking status as betweenparticipant factors, with block and condition as within-participant repeated measures and with variability in response time as a dependent variable, did not reveal any significant differences for interactions or main effects (Table 1).

Commission errors: The mean number of commission errors was significantly lower for the CPT than for the Go/NoGo condition. A four-way repeated measure ANCOVA revealed a significant effect for condition $[F(1,115)=8.64, P=0.004]$ with effect size $\eta 2$ $=0.07$. The number of commissions was significantly less for the CPT than for the Go/NoGo condition. No significant group effect was found. Yet, a marginal interaction effect was found for Group $\mathrm{x}$ Condition $[F(1,115)=3.71, p=0.057]$ with effect size $\eta 2=0.03$. The tattooed and non-tattooed groups had very similar commission error profiles in the CPT condition but in the Go/NoGo condition the tattooed group had more commission errors than the nontattooed one.

The effect of smoking habit was significant $[F(1,115)=7.17$, $P=0.009]$ with effect size $\eta 2=0.06$. Participants with a smoking habit had higher numbers of commission errors compared to nonsmokers (Figure 3). A three-way repeated measure ANCOVA was used with the group (tattooed and non-tattooed) and smoking status as between-participant factors, blocks (block 2 and block 3 ) 
as repeated measures, and education as a covariate, to assess the switch effect between CPT and Go/NoGo conditions. Participants in both groups showed a significant increase in commission errors following the switch from the CPT to the Go/NoGo condition $[F(1,115)=6.15, p=0.015]$, with effect size $\eta 2=0.051$. No significant group effect or interaction between Group and Switch were found (Figure 4).

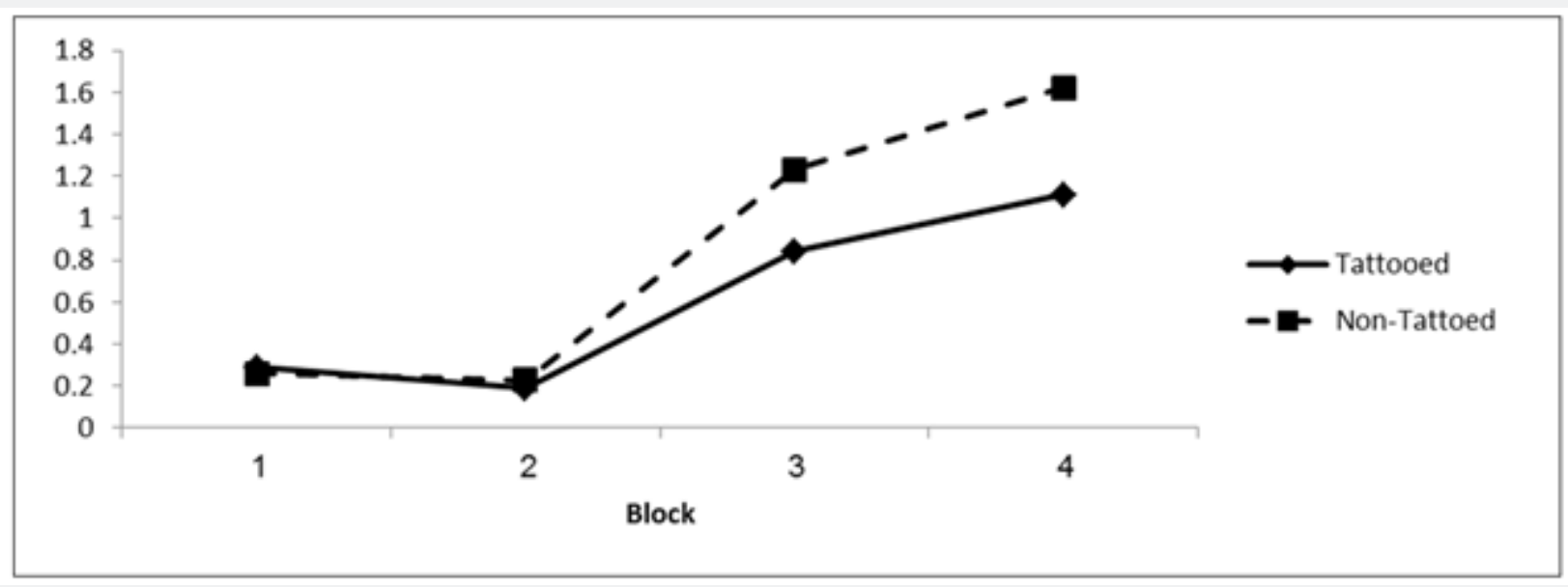

Figure 3: Number of commissions in tattooed and non-tattooed women

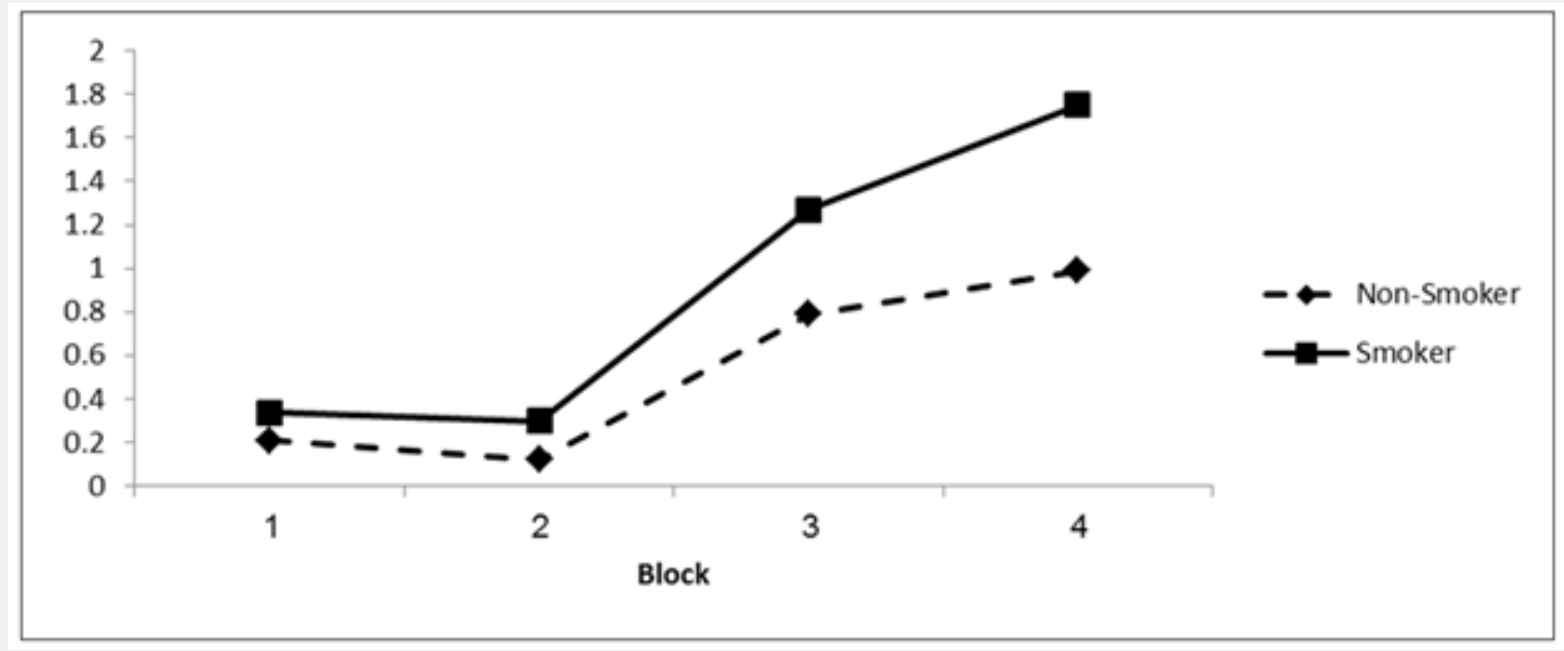

Figure 4: Number of commissions in smokers and non-smokers.

Omission: A Four - way ANCOVA with group (tattooed vs. non-tattooed) and smoking habit as between-participant factors, with block and condition as within-participant repeated measures and omission as dependent variable, did not reveal significant differences in interactions or main effects (Table 2). In tattooed women a significant correlation was found between slowness of response time in the Go/NoGo and CPT tasks with non-planning impulsivity scores of the BIS-11 (Table 2). No such correlation was found in the non-tattooed controls (Table 3).

\section{Discussion}

The purpose of this study was to determine if impairment in response inhibition can predict tattooing behavior in a sample of young women (college students or employed women). Our hypothesis was that failure to inhibit responses, as measured by the Go/NoGo task, would be associated with a tattooing behavior. To the best of our knowledge this is the first study of response inhibition in tattooed populations. The major finding of this study was that tattooed women were significantly slower 


\section{Psychology and Behavioral Science International Journal}

on the Go/NoGo task performance than non-tattooed women (Figure 1). Thus, it seems that in impulsive participants, the slowness of performance can be a consequence of difficulties in the organization of stimulus-response schemata $[34,35,49,51]$.
Similar to a previous study [52], the Go/NoGo response slowness was a more sensitive measure of inhibition impairment than the number of commission errors (Table 3).

Table 2: Correlation between the BIS-11 scores, the CPT and the Go/NoGo Response Time in the tattooed group.

\begin{tabular}{|c|c|c|c|c|}
\hline BIS & \multicolumn{2}{|c|}{ CPT } & \multicolumn{2}{c|}{ Go/NoGo } \\
Measures & Block 1 & Block 2 & Block 3 & Block 4 \\
\hline BIS Total & 0.23 & 0.21 & 0.16 & 0.22 \\
\hline AI & 0.17 & 0.09 & -0.05 & 0.03 \\
\hline MI & 0.06 & 0.04 & 0.01 & 0.06 \\
\hline NPI & $0.30^{*}$ & $0.35^{* *}$ & $0.39^{* *}$ & $0.41^{* *}$ \\
\hline
\end{tabular}

${ }^{* *} p<0.01,{ }^{*} p<0.05$

Note: BIS-11: Barratt impulsivity questionnaire, Al-attentional impulsiveness; MI-motor impulsiveness; NPI-non-planning impulsiveness.

Table 3: Correlation between the BIS-11 scores, the CPT and the Go/NoGo Response Time in the non-tattooed group.

\begin{tabular}{|c|c|c|c|c|}
\hline BIS & \multicolumn{2}{|c|}{ CPT } & \multicolumn{2}{c|}{ Go/NoGo } \\
\hline Measures & Block 1 & Block 2 & Block 3 & Block 4 \\
\hline BIS Total & 0.05 & 0.01 & -0.03 & -0.05 \\
\hline AI & 0.03 & 0.05 & -0.07 & -0.07 \\
\hline MI & -0.04 & 0 & -0.01 & 0.01 \\
\hline NPI & 0.1 & -0.03 & 0.01 & 0.15 \\
\hline
\end{tabular}

Note: BIS-11: Barratt impulsivity questionnaire, Al-attentional impulsiveness; MI-motor impulsiveness; NPI-non-planning impulsiveness.

In our study slow response time in the Go/NoGo task correlated with the elevated total and the non-planning impulsivity BIS-11 subscale scores. This correlation is not surprising, since the total BIS-11 score [53] and BIS-11 non-planning impulsivity subscale are associated with preference of immediate reward (de Wit et al., 2007) and impaired interference inhibition [41]. Moreover, elevated scores of the BIS-11 non-planning impulsivity subscale were reported previously to be associated with a reduction of grey matter volumes in the right orbitofrontal cortex (OFC) [42]. Both response inhibition control and goal-directed control of action selection [56] are governed by the OFC. We found that in the Go/NoGo condition only the tattooed group had tendency to make more commission errors than the non-tattooed one. Thus, it appears that impulsiveness among tattooed participants may be related, at least partially, to response inhibition impairment. Our finding that smoking status is strongly associated with tattooing behavior is in accordance with previous studies [23,27]. The main diagnostic characteristic of tobacco use disorder is the inability to refrain from smoking in spite of being aware of the adverse consequences. This represents a form of impulsivity with maladaptive consequences [22]. Similar to previous studies we found also in our sample that smoking women scored significantly higher on the BIS-11 than non-smoking women [58,59]. Furthermore, in accordance with previous studies, smokers demonstrated worse results on the measures of inhibition control in the Go/NoGo task than non-smokers [60,61] (Figure 2). The high level of impulsivity, as measured by both the BIS-11 scores and the Go/NoGo task, may contribute to the high rate of smoking in the tattooed women. Tattooing may be part of the addictive spectrum disorder since some tattooed subject tend to keep adding tattoos, similar to drug addicts who gradually increase the drug dosage [20]. However, it should be noted, the multivariate analyses suggest that the power of this relationship is small $[62,63]$.

\section{Limitations}

This study has several limitations that should be noted when interpreting the results. Our results may be confined to young women (aged 18-35 years) and cannot be applicable to the general population of subjects with tattooing behavior. Also, we did not examine relevant comorbid Axis I disorder such as attention-deficit/hyperactivity disorder or personality disorders in our young tattooed women, which may account for the increase impulsiveness. In addition, most of our women had relatively few tattoos. It is possible that heavy tattooing, or coexistence of pursing, may be associated with more severe inhibition impairments and higher levels of impulsiveness. Lastly, participants with alcohol or drug use comorbidities were excluded. The presence of both tattooing and substance use disorders may have additional impact on the Go/NoGo performance and on the BIS-11 scoring. 


\section{Conclusion and Future Directions}

Despite its limitations, the present study is the first attempt to clarify the complex relationship between cigarette smoking, impulsiveness and response inhibition measures in tattooed women. The current study has demonstrated that tattooed women exhibited lower response inhibition capacity and higher impulsiveness than non-tattooed controls. These impairments provide some evidence of a close association between response inhibition deficit and non-planning impulsiveness. These results suggest a justification for further efforts to identify neurocognitive factors contributing to the high rates of smoking among tattooed women. A future study should include individuals (men and women) with and without axis I disorders, including substance use disorders.

Declaration of Interests: SK is an employee of Anima Scan Ltd. Neither financial nor material support was received from any external resource for this work.

Authors' contributions: SK has built the design of the study and methods used for the study and the interpretation of results, drafted the manuscript and contributed to the final manuscript. AK recruited participants, conducted the interviews and contributed to the final manuscript. MV coded and analyzed the data. $\mathrm{OH}$ analyzed the data. Supervised the manuscript writing: $\mathrm{RL}$ and AW. All authors read and approved the final manuscript.

\section{References}

1. Heywood W, Patrick K, Smith AM, Simpson JM, Pitts MK, et al. (2012) Who gets tattoos? Demographic and behavioral correlates of ever being tattooed in a representative sample of men and women. Ann Epidemiol 22(1): 51-56.

2. Grumet GW (1983) Psychodynamic implications of tattoos. Am J Orthopsychiatry 53(3): 482-492.

3. Iannaccone M, Cella S, Manzi SA, Visconti L, Manzi F, et al. (2013) My body and me: self-injurious behaviors and body modifications in eating disorders-preliminary results. Eat Disord 21(2): 130-139.

4. Armstrong M, Pace MK (1997) Tattooing: another risk-behavior in adolescents warranting national health teaching. Appl Nurs Res 10(4): 181-189.

5. Roberts TA, Ryan SA (2002) Tattooing and high-risk behavior in adolescents. Pediatrics 110(6): 1058-1063.

6. Blackburn J, Cleveland J, Griffin R, Davis GG, Lienert J, et al. (2012) Tattoo frequency and types among homicides and other deaths, 20072008: a matched case-control study. Am J Forensic Med Pathol 33(3): 202-205.

7. Carson HJ (2014) The medium, not the message. How tattoos correlate with early mortality. Am J Clin Pathol 142(1): 99-103.

8. Dhossche D, Snell KS, Larder S (2000) A case-control study of tattoos in young suicide victims as a possible marker of risk. J Affect Disord 59(2): 165-168.

9. Koch JR, Roberts AE, Armstrong ML, Owen DC (2006) College students, tattoos, and sexual activity. Psychol Rep 97(3): 887-890.

10. Komar D, Lathrop S (2008) Tattoo types and frequencies in New Mexican white hispanics and white non-hispanics: autopsy data from homicidal and accidental deaths, 2002-2005. Am J Forensic Med Pathol 29(4): 285-289.
11. Byard RW, Charlwood C (2014) Commemorative tattoos as markers for anniversary reactions and suicide. J Forensic Leg Med 24: 15-17.

12. Owen DC, Armstrong ML, Koch JR, Roberts AE (2013) College students with body art: well-being or high-risk behavior? J Psychosoc Nurs Ment Health Serv 51(10): 20-28.

13. Bender TW, Gordon KH, Bresin K, Joiner Jr TE (2011) Impulsivity and suicidality: The mediating role of painful and provocative experiences. J Affect Disord 129(1-3): 301-307.

14. Yen CF, Hsiao RC, Yen JY, Yeh YC, Wang PW, et al. (2012) Tattooing among high school students in southern Taiwan: The prevalence, correlates and associations with risk-taking behaviors and depression. Kaohsiung J Med Sci 28(7): 383-389.

15. Braithwaite R, Robillard A, Woodring T, Stephens T, Arriola KJ (2001) Tattooing and body piercing among adolescent detainees: relationship to alcohol and other drug use. J Subst Abuse 13(1-2): 5-16.

16. Kuczkowski K (2003) Diagnostic tattoo in a parturient with «ecstasy» use. Anaesthesia 58(12): 1251-1252.

17. Carroll ST, Riffenburgh RH, Roberts TA, Myhre EB (2002) Tattoos and body piercings as indicators of adolescent risk-taking behaviors. Pediatrics 109(6): 1021-1027.

18. Brooks TL, Woods ER, Knight JR, Shrier LA (2003) Body modification and substance use in adolescents: is there a link? JAdolesc Health 32(1): 44-49.

19. Deschesnes M, Finès P, Demers S (2006) Are tattooing and body piercing indicators of risk-taking behaviours among high school students? J Adolesc 29(3): 379-393.

20. Wohlrab S, Stahl J, Kappeler PM (2007) Modifying the body: Motivations for getting tattooed and pierced. Body Image 4(1): 87-95.

21. Stirn A, Oddo S, Peregrinova L, Philipp S, Hinz A (2011) Motivations for body piercings and tattoos the role of sexual abuse and the frequency of body modifications. Psychiatry Res 190(2-3): 359-363.

22. Moeller FGM, Barratt ES, Dougherty DM, Schmitz JM, Swann AC (2001) Psychiatric aspects of impulsivity. Am J Psychiatry 158(11): 17831793.

23. Logan GD, Schachar RJ, Tannock R (1997) Impulsivity and inhibitory control. Psychol Sci 8(1): 60-64.

24. Bari A, Robbins TW (2013) Inhibition and impulsivity: Behavioral and neural basis of response control. Prog Neurobiol 108: 44-79.

25. Gorenstein EE, Newman JP (1980) Disinhibitory psychopathology: A new perspective and a model for research. Psychol Rev 87(3): 301-315.

26. Bosello R, Favaro A, Zanetti T, Soave M, Vidotto G, et al. (2010) Tattoos and piercings in adolescents: family conflicts and temperament. Riv Psichiatr 45(2): 102-106.

27. Drews DR, Allison CK, Probst JR (2000) Behavioral and self-concept differences in tattooed and nontattooed college students. Psychol Rep 86(2): 475-481.

28. Kvaavik E, Rise J (2012) How do impulsivity and education relate to smoking initiation and cessation among young adults? J Stud Alcohol Drugs 73(5): 804-810.

29. Pitts SR, Leventhal AM (2012) Associations of functional and dysfunctional impulsivity to smoking characteristics. J Addict Med 6(3): 226-232.

30. Terracciano A, Costa PT (2004) Smoking and the five-factor model of personality. Addiction 99(4): 472-481.

31. Smith JL, Mattick RP, Jamadar SD, Iredale JM (2014) Deficits in behavioural inhibition in substance abuse and addiction: A metaanalysis. Drug Alcohol Depend 145: 1-33. 
32. Stanford MS, Mathias CW, Dougherty DM, Lake SL, Anderson NE, et al (2009) Fifty years of the Barratt Impulsiveness Scale: An update and review. Pers Indiv Differ 47(5): 385-395.

33. Logan GD (1980) Attention and automaticity in Stroop and priming tasks: Theory and data. Cogn Psychol 12(4): 523-553.

34. Exposito J, Andres PA (1997) The effects of impulsivity on the perceptual and decision stages in a choice reaction time task. Pers Individ Dif 22: 693-697.

35. Keilp JG, Sackeim HA, Mann JJ (2005) Correlates of trait impulsiveness in performance measures and neuropsychological tests. Psychiatry Res 135(3): 191-201.

36. Vassileva J, Gonzalez R, Bechara A, Martin EM (2007) Are all drug addicts impulsive? Effects of antisociality and extent of multidrug use on cognitive and motor impulsivity. Addict Behav 32(12): 3071-3076.

37. Newman JP (1987) Reaction to punishment in extraverts and psychopaths: Implications for the impulsive behavior of disinhibited individuals. J Res Pers 21(4): 464-480.

38. Yechiam E, Goodnight J, Bates JE, Busemeyer JR, Dodge KA, et al (2006) A formal cognitive model of the Go/No-Go discrimination task: Evaluation and implications. Psychological Assessment 18(3): 239249.

39. Tullett AM, Inzlicht M (2010) The voice of self-control: Blocking the inner voice increases impulsive responding. Acta Psychologica 135(2): 252-256.

40. Bellgrove MA, Hester R, Garavan $H$ (2004) The functional neuroanatomical correlates of response variability: evidence from a response inhibition task. Neuropsychologia 42(14): 1910-1916.

41. Enticott PG, Ogloff JRP, Bradshaw JL (2006) Associations between laboratory measures of executive inhibitory control and self-reported impulsivity. Pers Individ Dif 41(2): 285-294.

42. Armstrong M, Murphy K, Sallee A, Watson M (2000) Tattooed Army soldiers: examining the incidence, behavior, and risk. Mil Med 165(2): 135-141.

43. Laumann A, Derrick A (2006) Tattoos and body piercings in the United States: A national data set. J Am Acad Dermatol 55(3): 413-421.

44. Armstrong M (1991) Career-oriented women with tattoos image. J Nurs Scholarship 23(4): 215-220.

45. Latreille J, Levy J, Guinot C (2011) Decorative tattoos and reasons for their removal: a prospective study in 151 adults living in South of France. J Eur Acad Dermatol Venereol 25(2): 181-187.

46. Kertzman S, Kagan A, Vainder M, Lapidus R, Weizman A (2013) Interactions between risky decisions, impulsiveness and smoking in young tattooed women. BMC Psychiatry 13: 278.

47. DeVito EE, Meda SA, Jiantonio R, Potenza MN, Krystal JH, et al. (2013) Neural correlates of impulsivity in healthy males and females with family histories of alcoholism. Neuropsychopharmacology 38(10): 1854-1863.
48. Perry RI, Krmpotich T, Thompson LL, Mikulich SK, Banich MT, et al. (2013) Sex modulates approach systems and impulsivity in substance dependence. Drug Alcohol Depend 133(1): 222-227.

49. Kertzman S, Lowengrub K, Aizer A, Vainder M, Kotler M, et al. (2008) Go-no-go performance in pathological gamblers. Psychiatry Res 161(1): 1-10.

50. Patton J, Stanford S, Barratt E (1995) Factor Structure of the Barratt Impulsiveness Scale. J Clin Psychol 51(6): 768-774.

51. Stuss DT, Alexander MP, Shallice T, Picton TW, Binns MA, et al. (2005) Multiple frontal systems controlling response speed. Neuropsychologia 43: 396-417.

52. Cheung AM, Mitsis EM, Halperin JM (2004) The relationship of behavioral inhibition to executive functions in young adults. J Clin Exp Neuropsychol 26: 393-404.

53. Hogarth L, Stillwell DJ, Tunney RJ (2013) BIS impulsivity and acute nicotine exposure are associated with discounting global consequences in the Harvard game. Hum Psychopharmacol Clin Exp 28: 72-79.

54. de Wit H, Flory JD, Acheson A, Mccloskey M, Manuck SB (2007) IQ and nonplanning impulsivity are independently associated with delay discounting in middle-aged adults. Pers Individ Dif 42: 111-121.

55. Matsuo K, Nicoletti M, Nemoto K, Hatch JP, Peluso MA, et al. (2009) A voxel-based morphometry study of frontal gray matter correlates of impulsivity. Hum Brain Mapp 30: 1188-1195.

56. Balleine BW, O'Doherty JP (2010) Human and rodent homologies in action control: corticostriatal determinants of goal-directed and habitual action. Neuropsychopharmacology 35: 48-69.

57. Dhar M, Wiersema JR, Pourtois G (2011) Cascade of neural events leading from error commission to subsequent awareness revealed using EEG source imaging. PLoS One 6(5): e19578.

58. Mitchell SH (1999) Measures of impulsivity in cigarette smokers and non-smokers. Psychopharmacology (Berl) 146(4): 455-464.

59. Rezvanfard M, Ekhtiari H, Mokri A, Djavid G, Kaviani H (2010) Psychological and behavioral traits in smokers and their relationship with nicotine dependence level. Arch Iran Med 13: 395-405.

60. Spinella M (2002) Correlations between orbitofrontal dysfunction and tobacco smoking. Addict Biol 7(4): 381-384.

61. Luijten M, Littel M, Franken IHA (2011) Deficits in inhibitory control in smokers during a Go/NoGo task: An investigation using event-related brain potentials. PLoS ONE 6(4): e18898.

62. DeJoy DM (1989) The optimism bias and traffic accident risk perception. Accid Anal Prev 21: 333-340.

63. Kahneman D, Tversky A (1979) Prospect theory-analysis of decision under risk. Econometrica 47: 263-291. 
(C) Commons Attribution 4.0 License

(C) DOI:10.19080/PBSIJ.2021.16.555937
Your next submission with Juniper Publishers will reach you the below assets

- Quality Editorial service

- Swift Peer Review

- Reprints availability

- E-prints Service

- Manuscript Podcast for convenient understanding

- Global attainment for your research

- Manuscript accessibility in different formats ( Pdf, E-pub, Full Text, Audio)

- Unceasing customer service

Track the below URL for one-step submission https://juniperpublishers.com/online-submission.php 